\title{
Short-term vascular hemodynamic responses to isometric exercise in young adults and in the elderly
}

This article was published in the following Dove Press journal:

Clinical Interventions in Aging

\author{
Renee Hartogl,* \\ Davide Bolignano ${ }^{1,2, *}$ \\ Eric Sijbrands' \\ Giacomo Pucci ${ }^{3,4}$ \\ Francesco Mattace-Raso' \\ 'Department of Internal Medicine, \\ Erasmus University Medical Center, \\ Rotterdam, the Netherlands; ${ }^{2}$ Institute \\ of Clinical Physiology, Italian National \\ Council of Research, Reggio Calabria, \\ Italy; ${ }^{3}$ Department of Medicine, \\ University of Perugia, Perugia, Italy; \\ ${ }^{4}$ Unit of Internal Medicine, Terni \\ University Hospital, Terni, Italy
}

*These authors contributed equally to this work
Background: Vascular aging is known to induce progressive stiffening of the large elastic arteries, altering vascular hemodynamics under both rest and stress conditions. In this study, we aimed to investigate changes in vascular hemodynamics in response to isometric handgrip exercise across ages.

Participants and methods: We included 62 participants, who were divided into three age categories: $20-40(n=22), 41-60(n=20)$, and $61-80(n=20)$ years. Vascular hemodynamics were measured using the Mobil-o-Graph ${ }^{\circledR}$ based on the pulsatile pressure changes in the brachial artery. One-way ANOVA test was performed to analyze the changes induced by isometric handgrip exercise.

Results: After isometric handgrip exercise, aortic pulse wave velocity (PWV) increased by $0.10 \mathrm{~m} / \mathrm{s}$ in the youngest, $0.06 \mathrm{~m} / \mathrm{s}$ in the middle-age, and $0.02 \mathrm{~m} / \mathrm{s}$ in the oldest age category. Changes in PWV strongly correlated with those in central systolic blood pressure (cSBP) ( $r=0.878, P<0.01$ ). After isometric exercise, the mean change of systolic blood pressure (SBP) was $-1.9 \%$ in the youngest, $0.6 \%$ in the middle-aged, and $8.2 \%$ in the oldest subjects. Increasing handgrip strength was associated with an increase in SBP and cSBP $(1.08$ and $1.37 \mathrm{mmHg}$ per $1 \mathrm{~kg}$ increase in handgrip strength, respectively, $P=0.01$ ). Finally, PWV was significantly associated with increasing handgrip strength with an increase of $0.05 \mathrm{~m} / \mathrm{s}$ per $1 \mathrm{~kg}$ higher handgrip strength $(P=0.01)$.

Conclusion: This study found increased blood pressure levels after isometric challenge and a strong association between handgrip strength and change in blood pressure levels and aortic stiffness in elderly subjects.

Keywords: vascular aging, isometric stress, blood pressure, pulse wave velocity

\section{Introduction}

During isometric exercise, the autonomic nervous system elicits a cardiovascular response by an increase in the sympathetic nerve activity. The following two neural systems contribute to sympathetic activation: the "central command" and the "exercise pressor reflex". ${ }^{1}$ Signals arising in the motor cortex activate both the cardiovascular control areas, to modulate sympathetic and parasympathetic activities, and skeletal muscle contraction. ${ }^{2}$ The exercise pressor reflex (or muscle reflex) is generated by the contraction of skeletal muscle via mechanically (muscle mechanoreflex) and chemically (muscle metaboreflex) skeletal muscle receptors. ${ }^{3}$ During handgrip exercise, the pressor reflex occurs when the muscle fatigues and/or when there is a mismatch between blood supply and metabolic demand. ${ }^{4}$ While the increase in arterial pressure during isometric exercise is a well-established response, ${ }^{5}$ the response of other vascular hemodynamics to exercise, such as arterial stiffness, is yet unclear. 
Age is the most important determinant for changes in the cardiovascular system. Vascular aging results in the loss of elastic properties, which leads to progressive stiffness of the large elastic arteries. ${ }^{6}$

Several studies have shown that arterial stiffness is an independent predictor of chronic heart disease, ${ }^{7,8}$ stroke, ${ }^{8,9}$ all-cause mortality, and cardiovascular mortality ${ }^{10}$ in hypertensive patients, and it is associated with increased risk for cardiovascular events in the general population. ${ }^{11,12}$ Measurement of pulse wave velocity (PWV) is the leading noninvasive method of assessing arterial stiffness, which is calculated by dividing the pulse distance traveled by the time traveled. ${ }^{13}$ Data on the effects of isometric exercise on arterial stiffness are limited. Several studies found an increase in central large artery stiffness in response to isometric handgrip exercise in hypertensive ${ }^{14}$ and healthy participants, ${ }^{14-16}$ suggesting that the increase in arterial stiffness could be due to the increased vasoconstriction from sympathetic system activation. However, these studies included participants within a range of age between 30 and 54 years. Since age is an important determinant for stiffening of the elastic arteries, it is interesting to explore the effect of aging on vascular hemodynamics in response to isometric exercise. We hypothesized that changes might be more pronounced in elderly than in young adults due to an altered autonomic response. Therefore, we investigated the changes in vascular hemodynamics in response to isometric handgrip exercise in persons of different ages.

\section{Participants and methods Subjects}

We included 62 participants aged $20-80$ years. The participants were students, employees, and apparently healthy patients from the Section of Geriatric Medicine of the Erasmus University Medical Center. Written informed consent was obtained from all participants, and the study was approved by the local medical ethics committee of the Erasmus University Medical Center (MEC 2014-336).

\section{Protocol}

The participants entered the room and were instructed to assume a supine position. An inflatable cuff was placed on the dominant arm. After 5 min of rest, baseline data were acquired using the Mobil-o-Graph ${ }^{\circledR}$ device. Patients were asked to perform the maximum handgrip trial in the standing position with their arms along their body. Maximal handgrip strength was the highest score recorded. Handgrip strength was measured using a strain-gaged dynamometer (TKK
5401; Takei Scientific Instruments Co., Ltd., Nigata City, Japan). Participants performed a maximum voluntary contraction using a handgrip dynamometer held in the dominant hand for $30 \mathrm{~s}$. After $30 \mathrm{~s}$ of rest, the vascular hemodynamics was measured.

\section{Measurements}

The Mobil-o-Graph ${ }^{\circledR}$ is an oscillometric blood pressure measurement validated device able to measure vascular hemodynamics such as central and peripheral blood pressure, augmentation index (AIx), and PWV. ${ }^{17}$ Measurements of PWV and AIx are based on the pulsatile pressure changes in the brachial artery. The pressure cuff sensors the first systolic peak of the pulse wave, which corresponds to the ejection of the blood volume into the aorta. The second systolic peak represents the reflection of the pulse wave from the periphery. PWV can be calculated by dividing the difference in time, between the beginning of the first and second systolic peaks, and the distance from the jugular notch to the symphysis. AIx is the difference between the amplitudes of the first and second systolic peaks. Estimates of PWV are derived using ARC Solver algorithms.

\section{Statistical analysis}

All descriptive data are reported as mean \pm standard error (SE). Differences in baseline hemodynamics were investigated by ANOVA. We investigated possible changes of blood pressure levels, heart rate, cardiac output, total peripheral resistance (TPR), Aix, and PWV-induced handgrip exercise with two-way ANOVA analyses in the three different categories of ages with models adjusted for age, sex, and the baseline corresponding hemodynamic value (ie, baseline systolic blood pressure [SBP] was included in models investigating changes of SBP levels). We investigated correlations between hemodynamic changes and handgrip strength with the linear regression. The level of significance was taken as $P<0.05$. Analyses were performed using IBM SPSS Statistics for Windows, Version 21.0.

\section{Results}

Table 1 shows the mean values for the characteristics of the participants. The mean age of the youngest, middle-aged, and oldest subjects was $28.8 \pm 5.5,49.8 \pm 5.9$, and $71.0 \pm 5.6$ years, respectively. The results of the hemodynamic measurements at baseline are presented in Table 2 . We found a statistically significant difference in PWV $(P$ for trend $<0.01)$ and in pulse pressure $(\mathrm{PP})$ between groups $(P$ for trend $<0.05)$ 
Table I Clinical characteristics of study participants

\begin{tabular}{llll}
\hline Variables & $\begin{array}{l}\text { Age 20-40 years, } \\
(\mathbf{n = 2 2})\end{array}$ & $\begin{array}{l}\text { Age 4I-60 years, } \\
(\mathbf{n = 2 0})\end{array}$ & $\begin{array}{l}\text { Age 6I-80 years, } \\
(\mathbf{n}=\mathbf{2 0})\end{array}$ \\
\hline Age (years), mean \pm SD & $28.8 \pm 5.5$ & $49.8 \pm 5.9$ & $71.0 \pm 5.6$ \\
Sex, male $(\%)$ & 50 & 50 & 60 \\
Height $(\mathrm{cm})$, mean \pm SD & $175 \pm 10$ & $171 \pm 16$ & $173 \pm 10$ \\
Weight $(\mathrm{kg})$, mean \pm SD & $76 \pm 13$ & $83 \pm 27$ & $80 \pm 14$ \\
Body mass index $\left(\mathrm{kg} / \mathrm{m}^{2}\right)$, mean \pm SD & $24.7 \pm 4.1$ & $25.9 \pm 3$ & $26.7 \pm 4.3$ \\
\hline
\end{tabular}

at baseline. No differences were found in SBP or diastolic blood pressure (DBP) between groups. There was no difference in maximum handgrip strength between groups with $31.2 \pm 5 \mathrm{~kg}$ in the youngest, $32.5 \pm 2.2 \mathrm{~kg}$ in the middle-aged, and $29.7 \pm 5.4 \mathrm{~kg}$ in the oldest ( $P$ for trend $=0.748$ ) subjects .

\section{Changes in vascular hemodynamics induced by isometric handgrip exercise}

Figure 1 presents the changes in hemodynamic parameters after handgrip exercise. After isometric exercise, the mean change of SBP (Figure 1A) was $-1.9 \%$ in the youngest, $0.6 \%$ in the middle-aged, and $8.2 \%$ in the oldest subjects. The differences in the mean change of SBP between the youngest, middle-aged, and oldest participants were statistically significant $(P=0.03$ and 0.01$)$.

The mean change in DBP (Figure 1B) after handgrip exercise was $0.7 \%$ in the youngest, $0.3 \%$ in the middle-aged, and $6.9 \%$ in the oldest subjects. The difference in mean change of DBP between middle-aged and oldest participants was significant $(P<0.02)$. We found no difference in mean change of PP (Figure 1C) between the youngest, middle-aged, and oldest subjects $(-9 \%,-1 \%$, and $14 \%$, respectively).
The mean change in AIx (Figure 1E) after handgrip exercise was $-50 \%$ in the youngest, $35 \%$ in the middle-aged, and $80 \%$ in the oldest subjects. The difference in mean change of AIx between young and oldest subjects was statistically significant $(P<0.046)$. After isometric exercise, all subjects show a nonsignificant decrease in $\mathrm{CO}$ (Figure 1F) and a nonsignificant increase in TPR (Figure 1G). No difference was found in mean change of PWV after handgrip between subjects with $-0.83 \%$ in the youngest, $1.0 \%$ in the middleaged, and $2.21 \%$ in the oldest subjects.

\section{Relationship between handgrip strength and changes in vascular hemodynamics}

Table 3 shows the association between handgrip strength and vascular hemodynamics in the youngest, middle-aged, and oldest subjects. In the youngest and middle-aged subjects, we found no association between handgrip strength and change in vascular hemodynamics. We found an association between handgrip strength and the change in SBP, PP, central SBP (cSBP), central PP (cPP), and PWV in the oldest subjects. Increasing handgrip strength was associated with an increase in SBP and cSBP (1.08 and $1.37 \mathrm{mmHg}$ per $1 \mathrm{~kg}$ higher

Table 2 Hemodynamic parameters at baseline

\begin{tabular}{|c|c|c|c|c|}
\hline Variables & $\begin{array}{l}\text { Age } 20-40 \text { years } \\
(n=22)\end{array}$ & $\begin{array}{l}\text { Age } 41-60 \text { years } \\
(n=20)\end{array}$ & $\begin{array}{l}\text { Age } 6 I-80 \text { years } \\
(n=20)\end{array}$ & $P$-value* \\
\hline $\mathrm{SBP}(\mathrm{mmHg})$ & $119 \pm 7.9$ & $123 \pm 3.4$ & $132 \pm 8.4$ & 0.59 \\
\hline $\mathrm{DBP}(\mathrm{mmHg})$ & $80 \pm 4.6$ & $8 I \pm 2.0$ & $76 \pm 4.9$ & 0.46 \\
\hline Pulse pressure $(\mathrm{mmHg})$ & $39 \pm 5.3$ & $42 \pm 2.3$ & $56 \pm 5.6$ & 0.05 \\
\hline MAP (mmHg) & $95 \pm 9$ & $100 \pm 11$ & $105 \pm 14$ & 0.96 \\
\hline Heart rate (bpm) & $68 \pm 4.6$ & $60 \pm 2.0$ & $62 \pm 4.9$ & 0.17 \\
\hline $\mathrm{cSBP}(\mathrm{mmHg})$ & $\mathrm{II} I \pm 7.5$ & $115 \pm 3.3$ & $124 \pm 8.0$ & 0.54 \\
\hline cDBP $(\mathrm{mmHg})$ & $80 \pm 4.6$ & $82 \pm 2.0$ & $77 \pm 4.9$ & 0.45 \\
\hline Central pulse pressure $(\mathrm{mmHg})$ & $3 \mid \pm 5.0$ & $33 \pm 2.2$ & $47 \pm 5.4$ & 0.03 \\
\hline Augmentation index at $75 \%$ & $12 \pm 8.3$ & $25 \pm 3.6$ & $24 \pm 8.8$ & 0.24 \\
\hline Cardiac output (L/min) & $5.2 \pm 0.5$ & $4.6 \pm 0.2$ & $5.0 \pm 0.5$ & 0.09 \\
\hline TPR (s mmHg/min) & $1.08 \pm 0.22$ & $1.36 \pm 0.23$ & $1.35 \pm 0.27$ & 0.10 \\
\hline Aortic PWV (m/s) & $7.6 \pm 0.3$ & $7.0 \pm 0.1$ & $8.2 \pm 0.3$ & 0.00 \\
\hline Handgrip strength (kg) & $31.2 \pm 5.0$ & $32.5 \pm 2.2$ & $29.7 \pm 5.4$ & 0.75 \\
\hline
\end{tabular}

Notes: $* P$-value for trend. Data are shown as mean $\pm S D$.

Abbreviations: cDBP, central DBP; cSBP, central SBP; DBP, diastolic blood pressure; MAP, mean arterial pressure; PWV, pulse wave velocity; SBP, systolic blood pressure; TPR, total peripheral resistance. 
A



C 20

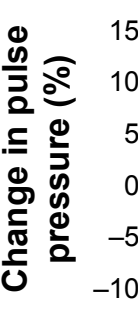

$-15$
B
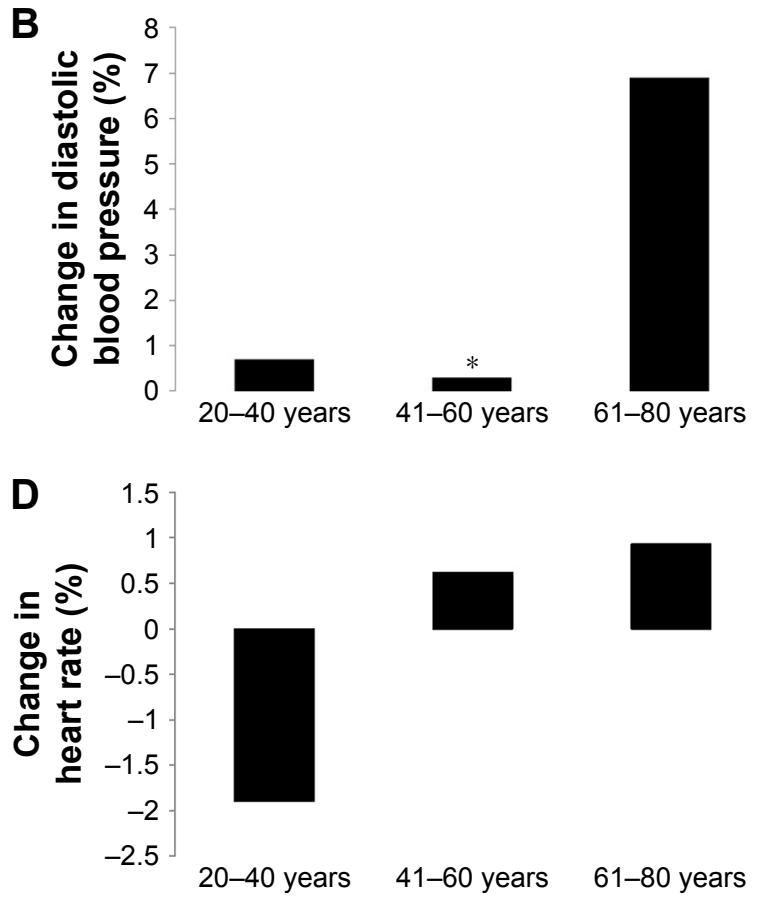

F

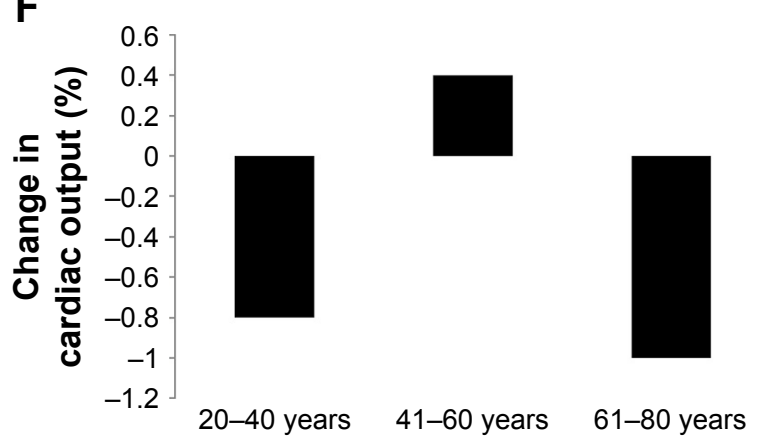

G

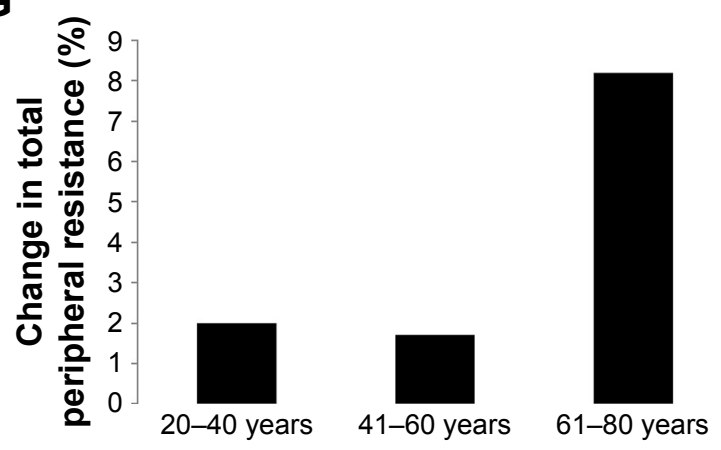

H

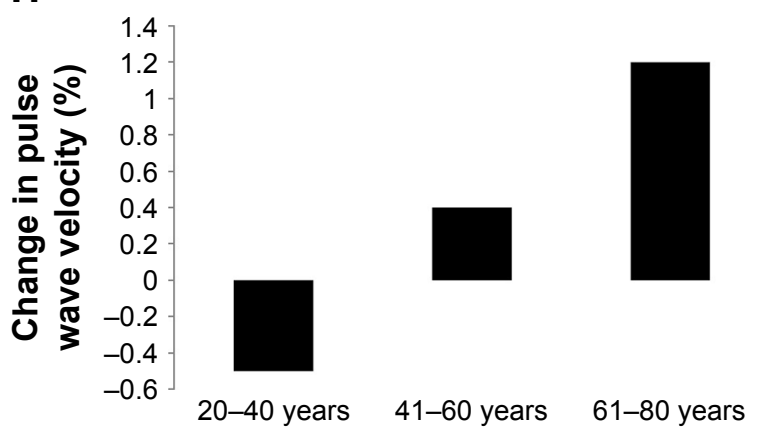

Figure I Change in systolic blood pressure (A), diastolic blood pressure (B), pulse pressure (C), heart rate (D), augmentation index (E), cardiac output (F), total peripheral resistance $(\mathbf{G})$, and pulse wave velocity $(\mathbf{H})$ before and after handgrip exercise.

Notes: $(\mathbf{A}) * A g e \quad 20-40$ vs $6 I-80$ years $(P=0.0 I)$. **Age $20-40$ vs $4 I-60$ years $(P=0.03)$. (B) *Age $4 I-60$ vs $6 I-80$ years $(P=0.02)$. $(E) * A g e 20-40$ vs $6 I-80$ years $(P=0.46)$.

in handgrip strength, respectively, $P=0.01)$. This means that per $10 \mathrm{~kg}$ handgrip strength, SBP and cSBP increase with 10.8 and $13.7 \mathrm{mmHg}$, respectively. The association between increasing handgrip strength and the change in PP and $\mathrm{cPP}$ was also significant $(P=0.01)$. With an increase of $1 \mathrm{~kg}$ handgrip strength, PP increased with $1.19 \mathrm{mmHg}$ while cPP increased with $1.46 \mathrm{mmHg}$. Finally, PWV was significantly associated with increasing handgrip strength with an increase of $0.05 \mathrm{~m} / \mathrm{s}$ per $1 \mathrm{~kg}$ increased handgrip strength $(P=0.01)$. 
Table 3 Delta hemodynamic parameters as determinants of handgrip strength in the youngest, middle-aged, and oldest subjects

\begin{tabular}{|c|c|c|c|c|c|c|c|c|c|}
\hline & \multicolumn{9}{|c|}{ Handgrip strength (kg) } \\
\hline & \multicolumn{3}{|c|}{$20-40$ years $(n=22)$} & \multicolumn{3}{|c|}{$4 I-60$ years $(n=20)$} & \multicolumn{3}{|c|}{$6 \mathrm{I}-80$ years $(n=20)$} \\
\hline & B & SE & $P$-value & B & SE & $P$-value & B & SE & $P$-value \\
\hline$\triangle \mathrm{SBP}(\mathrm{mmHg})$ & 0.20 & 0.12 & 0.12 & 0.15 & 0.16 & 0.34 & 1.08 & 0.36 & $0.0 I^{*}$ \\
\hline$\triangle \mathrm{DBP}(\mathrm{mmHg})$ & -0.04 & 0.10 & $0.7 \mathrm{I}$ & 0.09 & 0.09 & 0.31 & -0.10 & 0.23 & 0.66 \\
\hline$\Delta \mathrm{PP}(\mathrm{mmHg})$ & 0.24 & 0.14 & 0.11 & 0.06 & 0.14 & 0.65 & 1.19 & 0.40 & $0.01 *$ \\
\hline$\Delta$ Heart rate $(\mathrm{bpm})$ & -0.00 & 0.11 & 0.99 & -0.02 & 0.06 & 0.70 & 0.12 & 0.34 & 0.74 \\
\hline$\Delta \mathrm{cSBP}(\mathrm{mmHg})$ & 0.16 & 0.20 & 0.44 & 0.20 & 0.16 & 0.23 & 1.37 & 0.44 & $0.01 *$ \\
\hline$\Delta \mathrm{cDBP}(\mathrm{mmHg})$ & -0.02 & 0.10 & 0.82 & 0.07 & 0.09 & 0.48 & -0.07 & 0.21 & 0.76 \\
\hline$\Delta \mathrm{cPP}(\mathrm{mmHg})$ & 0.18 & 0.20 & 0.38 & 0.12 & 0.18 & 0.51 & 1.46 & 0.49 & $0.0 I^{*}$ \\
\hline$\Delta$ Alx at $75 \%$ & $0.4 I$ & 0.57 & 0.48 & 0.57 & 0.41 & 0.18 & -0.32 & 1.19 & 0.79 \\
\hline$\Delta \mathrm{CO}(\mathrm{L} / \mathrm{min})$ & -0.03 & 0.03 & 0.29 & -0.00 & 0.02 & 0.89 & 0.02 & 0.06 & 0.72 \\
\hline$\Delta \mathrm{TPR}(\mathrm{s} \mathrm{mmH} / \mathrm{g} / \mathrm{min})$ & 0.01 & 0.01 & 0.24 & 0.00 & 0.01 & 0.86 & 0.00 & 0.02 & 0.91 \\
\hline$\Delta \mathrm{PWV}(\mathrm{m} / \mathrm{s})$ & 0.01 & 0.01 & 0.19 & 0.01 & 0.01 & 0.20 & 0.05 & 0.02 & $0.01 *$ \\
\hline
\end{tabular}

Note: $* P$-value $<0.05$.

Abbreviations: Alx, augmentation index; B, beta; c, central; CDBP, central DBP; CO, cardiac output; cPP, central pulse pressure; cSBP, central SBP; DBP, diastolic blood pressure; PP, pulse pressure; PWV, pulse wave velocity; SE, standard error; SBP, systolic blood pressure; TPR, total peripheral resistance.

\section{Discussion}

In the present study, we found increased blood pressure levels after isometric challenge in elderly subjects. We also found a strong association between handgrip strength and the change in blood pressure levels and aortic stiffness in the older subjects; we did not observe this association in the youngest or middle-aged subjects.

Previous studies have shown an increase in blood pressure levels after isometric handgrip exercise in normotensive and hypertensive individuals ${ }^{14}$ in healthy young subjects ${ }^{16,18,19}$ and older subjects, ${ }^{20}$ who also observed that hemodynamic changes can considerably vary among individuals. ${ }^{18}$ Within the framework of a relatively large community-based longitudinal study, Taekema et $\mathrm{al}^{21}$ investigated the possible relation between blood pressure and handgrip strength in the middle-aged (63 years) and old subjects ( 85 years), finding an association between handgrip strength and high SBP and PP only in the oldest subjects. According to Taekema, we also found increased blood pressure levels after isometric challenge to be more pronounced in elderly subjects; moreover, we found a strong association between handgrip strength and aortic stiffness.

Several mechanisms can explain our results. First, the observed changes in blood pressure in the elderly can be explained due to failure of the aging arterial system during stress. During isometric exercise, the autonomic nervous system elicits a cardiovascular response, which increases the sympathetic nerve activity, arterial blood pressure, and heart rate, and changes the distribution of blood flow. ${ }^{1}$ The arterial system in younger subjects is capable of receiving spurts from the left ventricle of blood during isometric exercise and distributes these trough peripheral capillaries. Elastin fibers in the arterial wall minimize the fluctuations in the blood flow. Vascular aging results in the loss of elastic properties, which leads to progressive stiffness of the large elastic arteries. Stiffening leads to an increase in SBP and a decrease in DBP, which stresses the small arterial vessels causing damage to particularly the coronary arteries, kidney, and brain. ${ }^{22}$ We found a statistically significant increase in PP and aortic stiffness with increasing age at baseline. We found significant differences in the change of SBP and DBP after exercise between the middle-aged and oldest subjects with more pronounced changes in the oldest subject.

The present study has some limitations. First, we included a relatively small number of participants. Second, we performed measurements only once so we cannot exclude variation over time. The strength of this study is that we performed our measurements following standard procedure; in this way, we think that exposure was similar for all participants. Moreover, we used a brachial cuff-based oscillometric device, which has been shown to be reproducible, ${ }^{23}$ acceptable accurate when compared with other invasive methods, ${ }^{24}$ and useful for routine clinical practice. ${ }^{25}$

\section{Conclusion}

We found increased blood pressure levels after isometric challenge and a strong association between handgrip strength and change in blood pressure levels and aortic stiffness in elderly subjects. These findings can be possibly explained by failure of the aging arterial system during stress and increased vascular resistance with increasing age. 


\section{Disclosure}

The authors report no conflicts of interest in this work.

\section{References}

1. Mitchell JH, Kaufman MP, Iwamoto GA. The exercise pressor reflex: its cardiovascular effects, afferent mechanisms, and central pathways. Annu Rev Physiol. 1983;45:229-242.

2. Goodwin GM, McCloskey DI, Mitchell JH. Cardiovascular and respiratory responses to changes in central command during isometric exercise at constant muscle tension. J Physiol. 1972;226(1):173-190.

3. Smith SA, Mitchell JH, Garry MG. The mammalian exercise pressor reflex in health and disease. Exp Physiol. 2006;91(1):89-102.

4. Seals DR, Enoka RM. Sympathetic activation is associated with increases in EMG during fatiguing exercise. J Appl Physiol (1985). 1989; 66(1):88-95.

5. Rowell LB, O'Leary DS. Reflex control of the circulation during exercise: chemoreflexes and mechanoreflexes. J Appl Physiol (1985). 1990;69(2):407-418.

6. Jani B, Rajkumar C. Ageing and vascular ageing. Postgrad Med J. 2006; 82(968):357-362.

7. Boutouyrie P, Tropeano AI, Asmar R, et al. Aortic stiffness is an independent predictor of primary coronary events in hypertensive patients: a longitudinal study. Hypertension. 2002;39(1):10-15.

8. Mattace-Raso FU, van der Cammen TJ, Hofman A, et al. Arterial stiffness and risk of coronary heart disease and stroke: the Rotterdam Study. Circulation. 2006;113(5):657-663.

9. Laurent S, Katsahian S, Fassot C, et al. Aortic stiffness is an independent predictor of fatal stroke in essential hypertension. Stroke. 2003; 34(5):1203-1206.

10. Laurent S, Boutouyrie P, Asmar R, et al. Aortic stiffness is an independent predictor of all-cause and cardiovascular mortality in hypertensive patients. Hypertension. 2001;37(5):1236-1241.

11. Mitchell GF, Hwang SJ, Vasan RS, et al. Arterial stiffness and cardiovascular events: the Framingham Heart Study. Circulation. 2010; 121(4):505-511.

12. Willum-Hansen T, Staessen JA, Torp-Pedersen C, et al. Prognostic value of aortic pulse wave velocity as index of arterial stiffness in the general population. Circulation. 2006;113(5):664-670.

13. Laurent S, Cockcroft J, Van Bortel L, et al; European Network for Noninvasive Investigation of Large Arteries. Expert consensus document on arterial stiffness: methodological issues and clinical applications. Eur Heart J. 2006;27(21):2588-2605.
14. Chirinos JA, Segers P, Raina A, et al. Arterial pulsatile hemodynamic load induced by isometric exercise strongly predicts left ventricular mass in hypertension. Am J Physiol Heart Circ Physiol. 2010;298(2): H320-H330.

15. Lydakis C, Momen A, Blaha C, et al. Changes of central haemodynamic parameters during mental stress and acute bouts of static and dynamic exercise. J Hum Hypertens. 2008;22(5):320-328.

16. Geleris P, Stavrati A, Boudoulas H. Effect of cold, isometric exercise, and combination of both on aortic pulse in healthy subjects. Am J Cardiol. 2004;93(2):265-267.

17. Trachet B, Reymond P, Kips J, et al. Numerical validation of a new method to assess aortic pulse wave velocity from a single recording of a brachial artery waveform with an occluding cuff. Ann Biomed Eng. 2010;38(3):876-888.

18. Watanabe K, Ichinose M, Tahara R, Nishiyasu T. Individual differences in cardiac and vascular components of the pressor response to isometric handgrip exercise in humans. Am J Physiol Heart Circ Physiol. 2014;306(2):H251-H260.

19. Umeda M, Williams JP, Marino CA, Hilliard SC. Muscle pain and blood pressure responses during isometric handgrip exercise in healthy African American and non-Hispanic White adults. Physiol Behav. 2015; 138:242-246.

20. Lalande S, Sawicki CP, Baker JR, Shoemaker JK. Effect of age on the hemodynamic and sympathetic responses at the onset of isometric handgrip exercise. J Appl Physiol (1985). 2014;116(2):222-227.

21. Taekema DG, Maier AB, Westendorp RG, de Craen AJ. Higher blood pressure is associated with higher handgrip strength in the oldest old. Am J Hypertens. 2011;24(1):83-89.

22. O'Rourke MF, Hashimoto J. Mechanical factors in arterial aging: a clinical perspective. J Am Coll Cardiol. 2007;50(1):1-13.

23. Papaioannou TG, Argyris A, Protogerou AD, et al. Non-invasive 24 hour ambulatory monitoring of aortic wave reflection and arterial stiffness by a novel oscillometric device: the first feasibility and reproducibility study. Int J Cardiol. 2013;169(1):57-61.

24. Hametner B, Wassertheurer S, Kropf J, Mayer C, Eber B, Weber T. Oscillometric estimation of aortic pulse wave velocity: comparison with intra-aortic catheter measurements. Blood Press Monit. 2013;18(3): 173-176.

25. Nunan D, Fleming S, Hametner B, Wassertheurer S. Performance of pulse wave velocity measured using a brachial cuff in a community setting. Blood Press Monit. 2014;19(6):315-319.
Clinical Interventions in Aging

\section{Publish your work in this journal}

Clinical Interventions in Aging is an international, peer-reviewed journal focusing on evidence-based reports on the value or lack thereof of treatments intended to prevent or delay the onset of maladaptive correlates of aging in human beings. This journal is indexed on PubMed Central, MedLine,

\section{Dovepress}

CAS, Scopus and the Elsevier Bibliographic databases. The manuscript management system is completely online and includes a very quick and fair peer-review system, which is all easy to use. Visit http://www.dovepress. com/testimonials.php to read real quotes from published authors. 